\title{
Bacterial $\beta$-glucosidase reveals the structural and functional basis of genetic defects in human glucocerebrosidase 2 (GBA2)
}

Ratana Charoenwattanasatien ${ }^{\mathrm{a}, \mathrm{b}, \mathrm{c}, 1}$, Salila Pengthaisong ${ }^{\mathrm{b}, \mathrm{c}, 1}$, Imogen Breen $^{\mathrm{d}}$, Risa Mutoh ${ }^{\mathrm{a}}$, Sompong Sansenya ${ }^{\mathrm{e}}$, Yanling $\mathrm{Hua}^{\mathrm{c}}{ }^{\mathrm{f}}$, Anupong Tankrathok ${ }^{\mathrm{g}}$, Liang $\mathrm{Wu}^{\mathrm{d}}$, Chomphunuch Songsiriritthigul ${ }^{\mathrm{c}, \mathrm{h}}$, Hideaki Tanaka ${ }^{a}$, Spencer J. Williamsi, Gideon J. Davies ${ }^{\mathrm{d} *}$, Genji Kurisu ${ }^{\mathrm{a} *}$, James R. Ketudat Cairns ${ }^{\mathrm{b}, \mathrm{c}, \mathrm{j} *}$

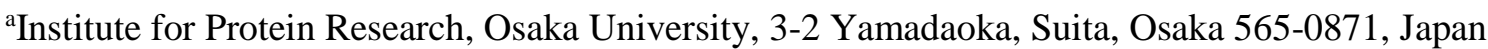

${ }^{\mathrm{b} S}$ School of Biochemistry, Institute of Science, Suranaree Univerity of Technology, Nakhon Ratchasima 30000, Thailand

'Center for Biomolecular Structure, Function and Application, Suranaree University of Technology, Nakhon Ratchasima 30000, Thailand

${ }^{\mathrm{d} S}$ Structural Biology Laboratory, Department of Chemistry, The University of York, YO10 5DD U.K.

e Department of Chemistry, Faculty of Science, Rajamangala University of Technology Thanyaburi, Pathum Thani 12110, Thailand

${ }^{\mathrm{f}}$ Center for Scientific and Technological Equipment, Suranaree University of Technology, Nakhon Ratchasima 30000, Thailand

'Department of Biotechnology, Faculty of Agro-Industrial Technology, Kalasin University, Kalasin 46000, Thailand

hynchrotron Light Research Institute, Nakhon Ratchasima 30000, Thailand

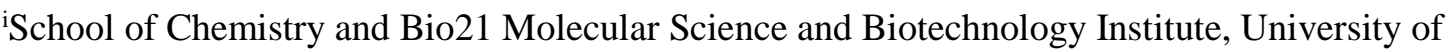
Melbourne, Parkville, Victoria 3010, Australia

jLaboratory of Biochemistry Chulabhorn Research Institute, Bangkok 10210, Thailand

${ }^{1}$ Should be considered co-first authors.

*Corresponding authors: GJD (gideon.davies@york.ac.uk), GK (gkurisu@ protein.osaka-u.ac.jp), JRKC (cairns@sut.ac.th). 


\section{Supporting Information}

\section{SI Text}

\section{Supporting Results and Discussion}

\section{Gene Constructs for Protein Expression:}

The $T x \mathrm{GH} 116$ protein was previously expressed as an N-terminally His 6 and S-tagged protein, but expression was relatively low and poor binding to the IMAC column suggested the Nterminal tag was lost. ${ }^{l}$ The N-terminal sequence resembled a transmembrane domain or eukaryotic signal sequence with a positively charged sequence followed by a hydrophobic stretch, but did not predict to be a signal sequence for Gram negative bacteria in SignalP, ${ }^{2}$ so this may indicate it was poorly recovered due to interaction with the Escherichia coli secretion machinery. New constructs were assembled by adding a C-terminal His 6 tag and cutting off the N-terminal 18, 157 or 400 amino acids showed that only the full-length and protein with the first 18 amino acids deleted (TxGH116 $\Delta 1$ 18) exhibited $\beta$-glucosidase activity, and that the 18 -amino acid truncated protein expressed at much higher levels.

Independently, an optimized gene was produced from expression from the pET28a plasmid with a simple N-terminal His-tag and the first 20 residues of the natural protein deleted, to produce the protein designated $T x \mathrm{GH} 116-\mathrm{N}$. This protein was crystallized and the crystals diffracted to determine the structure in the $P 6_{1}$ space group. Notably, although the monomer this structure was quite similar to the $P 22_{1} 2$ space group structure of TxGH116D18, the loop containing the catalytic acid/base had shifted approximately $2 \AA$ to move the catalytic acid/base further from the catalytic nucleophile, thereby indicating the flexibility of this loop.

\section{Structural comparison:}

TxGH116 shows no structural similarity to other retaining $\beta$-glucosidases. The glycoside hydrolase $(\mathrm{GH})$ clan GH-A families, including GH1, GH2, GH5, and GH30, possess $(\beta / \alpha)_{8}$-barrel catalytic domains, while the active site in family GH3 is located between a $(\beta / \alpha)_{8}$-barrel and a $\beta$ sandwich domain (Figure S2A). Superposition of the catalytic nucleophiles, and covalently-linked sugar-like inhibitors (G2F in the case of $T x \mathrm{GH} 116)$, from structural representatives of these families reveals a unique position for the general acid/base of TxGH116, above carbons 3 and 4 of the pyranose ring, whereas in clan GH-A enzymes (comprising GH1, 5 and 30) it is located lateral to the ring on the $\mathrm{C} 1-\mathrm{C} 2$ bond side, and in $\mathrm{GH} 3$ enzymes is located above the $\mathrm{C} 2-\mathrm{O} 2$ bond (Figure $\mathrm{S} 2 \mathrm{~B}$ ). In addition to the unique position of the general acid/base in $T x \mathrm{GH} 116$, the surrounding residues that interact with the glucosyl residue are completely different from those in the GH30 GBA1 (Figure S2C), yet are completely conserved between TxGH116 and GBA2 (Figure 3C). This unique active site structure may allow design of inhibitors for GBA2 that have little effect on GBA1 and other human $\beta$-glucosidases.

The overall structures of the Geobacillus thermoglucosidaseus GH family $52 \beta$-xylosidase $(G t \mathrm{GH} 52)^{3}$ and Thermoanaerobacterium xylanolyticum TxGH116 $\beta$-glucosidase are compared in Figure S3. These two structures share the same gross folds and domain structures, but differ in many details. The $G t \mathrm{GH} 52 \mathrm{~N}$-terminus is significantly shorter and lacks the first helix and the long loop that follows it and contributes to the active site cleft in $T x \mathrm{GH} 116$. The first small $\beta$-sheet is 2 strands in GtGH52 and 3 strands in $T x \mathrm{GH} 116$, while the smaller of the two sandwiched $\beta$-sheets has 6 strands in GtGH52, compared to 5 in $T x \mathrm{GH} 116$, due to inclusion of a short parallel $\beta$-strand on the end not found in $T x \mathrm{GH} 116$. A few short $\beta$-sheets are also found toward the end of the N-terminal domain and between the helices of the C-terminal domain in GtGH52, and are significantly displaced from the positions in $T x \mathrm{GH} 116$. Interestingly, although the structure of the long loop between the fifth and sixth loops that contains the catalytic acid/base is not very similar in overall structure, it contains a metal binding site (modeled as sodium in GtGH52) in nearly the same position as the metal site in 
Tx $\mathrm{GH} 116$, as well as having the catalytic acid/base in a similar position. Although GtGH52 $\beta$ xylosidase is a retaining enzyme, Espina et $a .^{3}$ noted that it shares significant structural similarity to inverting glycosidases and phosphorylases from families GH15, GH63, GH65, GH78, GH92, GH94, and GH95, a similarity shared with $T x \mathrm{GH} 116$.

\section{Evidence of catalytic mechanism and amino acid residues}

Since the putative catalytic residues for TxGH116 were considerably further apart than previously characterized retaining glycosidases, $\left(8 \AA\right.$ in the $P 2_{1} 2_{1} 2$ structure and $>10 \AA$ in the $P 6_{1}$ structure vs. $4.5-6.5 \AA$ in other retaining $\beta$-glucosidases), we sought to verify the retaining mechanism and catalytic residues. A time-course NMR study of the hydrolysis of 4NPGlc indeed showed that the initial sugar product was $\beta$-D-glucose (Figure S5A), thereby verifying that $T x \mathrm{GH} 116$, like other members of this family, uses a retaining mechanism. The catalytic activity of the TxGH116 variant E441A for hydrolysis of 4NPGlc was reduced by 50,000-fold relative to wild type (Table 1), and was rescued in a concentration-dependent manner by addition of formate or azide to give maximal enhancement of 1000-fold with $4 \mathrm{M}$ formate (Figure S5B). ${ }^{1} \mathrm{H}-\mathrm{NMR}$ analysis of the products with azide confirmed it was the $\alpha$-glucosyl azide $\left(\mathrm{H} 1: \delta 5.48 \mathrm{ppm}, \mathrm{d}, J_{1,2}=3.3 \mathrm{~Hz}\right.$; Figure S5E), as expected for rescue of a nucleophile mutant with a retaining mechanism (Figure S4B). ${ }^{4}$ Consistent with the role of D593 as an acid/base, the variant D593A possessed activity 39,000-fold lower than wild type on cellobiose, a substrate that requires general acid catalysis for the glycosylation step, but only 350 -fold lower activity on 4NPGlc, which requires less protonic assistance (Table 1). The activity of the D593A variant on 4NPGlc was enhanced approximately 10 -fold with $4 \mathrm{M}$ formate and 2 -fold with sodium azide (Figure S5C). In this case, the product with azide was $\beta$-glucosyl azide (H1: $\delta 4.62 \mathrm{ppm}, \mathrm{d}, J_{1,2}=8.6 \mathrm{~Hz}$; Figure S5F), again consistent with the retention of anomeric configuration expected for rescue of an acid/base mutant (Figure S4C). ${ }^{4}$ Collectively, these data support the assignment of E441 as the catalytic nucleophile and D593 as the general acid/base.

The computed free energy landscape analysis of glucoimidazole indicates that the barriers to adopting transition state mimicking planar conformations (half-chair, boat and envelope) are low and that the conformation observed on enzyme likely reflects the preference imposed by the enzyme. ${ }^{5}$ Taken together, the ${ }^{4} C_{1}$ conformation of the G2F complex can be considered to reveal the conformation of the glycosyl enzyme intermediate, and the GIM complex the conformation of the transition state, allowing proposal of a ${ }^{1} S_{3} \rightarrow{ }^{4} H_{3} /{ }^{4} E^{\ddagger} \rightarrow{ }^{4} C_{1}$ conformational itinerary for the glycosylation half reaction for GH1 16 enzymes, similar to that for other retaining $\beta$-glucosidases. ${ }^{6-9}$

\section{Supplemental Methods}

\section{Plasmid construction}

For the $T x \mathrm{GH} 116 \Delta 1-18$ construct, the previously described construct for full-length $T x \mathrm{GH} 116$ in pET30a ${ }^{l}$ was used as the template to PCR amplify the sequence encoding the $T x \mathrm{GH} 116$ without the stop codon with the primers T7_fwd and TxGH116_no_stop_rev, without the first 18 amino acids and the stop codon with the primers $T x \mathrm{GH} 116 \_19 \_$fwd and $T x \mathrm{GH} 116 \_n o \_s t o p \_r e v$, without the first 157 amino acids and the stop codon with the primers TxGH116_158_fwd and TxGH116_no_stop_rev, and without the first 400 amino acid residues and missing the stop codon primers TxGH116_401_fwd and TxGH116_no_stop_rev. The amplified DNA product bands were purified and cloned back into the pET30a plasmid to encode proteins that each contained an N-terminal His-tag, thrombin site, S-tag, and enterokinase site, and a C-terminal His-tag.

For the $T x \mathrm{GH} 116-\mathrm{N}$ construct, the gene encoding the GH116 protein from Thermoanaerobacterium xylanolyticum was purchased in a form codon optimised for $E$. coli expression. The gene was provided cloned into pET28a (30 $\mu \mathrm{g} / \mathrm{ml}$ kanamycin resistant) between $N d e \mathrm{I}$ and $\mathrm{XhoI}$ restriction sites. 


\section{Protein expression}

The pET30a/TxGH116 plasmids were transformed into BL21(DE3) E. coli and expressed at $20{ }^{\circ} \mathrm{C}$ and proteins extracted in lysis buffer as previously described for a related construct encoding the fulllength $T x \mathrm{GH} 116 .{ }^{l}$ After induction with $0.3 \mathrm{mM}$ IPTG at $20^{\circ} \mathrm{C}$ for $16-18 \mathrm{~h}$, the proteins were extracted and the soluble fraction evaluated for hydrolysis of 4-nitrophenyl $\beta$-D-glucopyranoside (4NPGlc) and by SDS-PAGE. Fractions with activity were further heated at $50^{\circ} \mathrm{C} 20 \mathrm{~min}$, then $70^{\circ} \mathrm{C} 20 \mathrm{~min}$, with insoluble protein removed by centrifugation after each step, and the soluble protein evaluated by the same methods. For production of selenomethionine-labeled $T x \mathrm{GH} 116$ (SeTxGH116), the pET30a/TxGH116 1 1-18 plasmid was transformed into E. coli strain B834(DE3) pLysS cells, and grown in SeMet core medium (Nihon Jyunyaku Co.) consisting of $10 \mathrm{~g}$ D-glucose, $20 \mathrm{~g}$ maltose monohydrate, $250 \mathrm{mg} \mathrm{MgSO} 4.7 \mathrm{H}_{2} \mathrm{O}, 4.175 \mathrm{mg} \mathrm{FeSO}{ }_{4} \cdot 7 \mathrm{H}_{2} \mathrm{O}, 5 \mathrm{mg}$ thiamine, $8.3 \mu \mathrm{L} \mathrm{H}_{2} \mathrm{SO}_{4}, 50 \mathrm{mg}$ ampicillin, $34 \mathrm{mg}$ chloramphenicol, and $25 \mathrm{mg}$ SeMet per liter. The cells were cultured at $37^{\circ} \mathrm{C}$ to achieve $\mathrm{OD}_{600} 0.5-0.6$ and then induced with $0.3 \mathrm{M} \mathrm{IPTG}$ at $20^{\circ} \mathrm{C}$ for $18 \mathrm{~h}$.

After heating at $70^{\circ} \mathrm{C}$, the soluble extract of $T x \mathrm{GH} 116 \Delta 1-18$ was purified by immobilized metal affinity chromatography (IMAC) on TALON cobalt affinity resin (Clontech). After washing with equilibration buffer $(150 \mathrm{mM} \mathrm{NaCl}, 20 \mathrm{mM}$ sodium phosphate, $\mathrm{pH} 7.4)$ and $5 \mathrm{mM}$ and $10 \mathrm{mM}$ imidazole in equilibration buffer, the specific protein was eluted with $250 \mathrm{mM}$ imidazole in equilibration buffer. The $250 \mathrm{mM}$ imidazole fraction containing $T x \mathrm{GH} 116$ protein was concentrated and the buffer exchanged to $150 \mathrm{mM} \mathrm{NaCl}, 20 \mathrm{mM}$ Tris, $\mathrm{pH}$ 8.0. The protein was digested with 0.006 $\mu \mathrm{g}$ enterokinase (New England Biolabs) per mg protein at $23{ }^{\circ} \mathrm{C}$ for $18 \mathrm{~h}$, then purified over a Superdex S200 gel filtration column in $500 \mathrm{mM} \mathrm{NaCl}, 20 \mathrm{mM}$ Tris, $\mathrm{pH}$ 8.0. Fractions containing Tx GH116 were pooled and the buffer exchanged to $150 \mathrm{mM} \mathrm{NaCl}, 20 \mathrm{mM}$ Tris, $\mathrm{pH} 8.0$, in a Centricon $30 \mathrm{kDa}$ MWCO centrifugal filter (Millipore Corp.). For production of TxGH116-N, The pET28a/TxGH116 plasmid was transformed into E. coli strain BL21(DE3) and the expression of the TxGH116 gene induced with $0.5 \mathrm{mM}$ IPTG at $16^{\circ} \mathrm{C}$ for $18 \mathrm{~h}$. Proteins were extracted by sonication at 14-18 Hz, four runs of 40-50 s exposure, in buffer A (50 mM HEPES pH 7.5, $500 \mathrm{mM} \mathrm{NaCl}, 20 \mathrm{mM}$ imidazole). The soluble fraction of $T x \mathrm{GH} 116-\mathrm{N}$ was purified by nickel affinity chromatography on a 5 $\mathrm{ml} \mathrm{GE}$ Healthcare HisTrap column, eluted with a gradient into buffer B (50 mM HEPES pH 7.5, 500 $\mathrm{mM} \mathrm{NaCl}, 500 \mathrm{mM}$ imidazole). The fractions containing $T x \mathrm{GH} 116-\mathrm{N}$ were pooled, concentrated and buffer exchanged into $50 \mathrm{mM}$ HEPES, $\mathrm{pH} 7.5,500 \mathrm{mM} \mathrm{NaCl}$. The protein was then purified over a Superdex S200 gel filtration column in $50 \mathrm{mM}$ HEPES pH 7.5, $500 \mathrm{mM} \mathrm{NaCl}$ and the fractions containing $T x \mathrm{GH} 116$ pooled, concentrated to $20 \mathrm{mg} / \mathrm{ml}$ in a $50 \mathrm{kDa}$ MWCO centrifugal filter (Millipore Corp.) and stored at $5{ }^{\circ} \mathrm{C}$.

Solution Analysis: Size Exclusion Chromatography - Multi-Angle Laser Light Scattering (SECMALLS) was used to determine the molecular mass of soluble-state TxGH116-N. A Superdex 200 HR 10/30 column was connected to an HPLC system, which was coupled to a DAWN Heleos light scattering instrument with a laser wavelength of $658.00 \mathrm{~nm}$ (Wyatt Technology). TxGH116-N (250 nmol) was run in buffer containing $50 \mathrm{mM}$ HEPES, $\mathrm{pH} 7.5,500 \mathrm{mM} \mathrm{NaCl}$ at $0.5 \mathrm{ml} / \mathrm{min}$ and the absolute masses of the particles in the solution determined with Wyatt software. Soluble TxGH116-N showed a major peak at a molar mass determined to be $1.66 \times 10^{5} \mathrm{~g} / \mathrm{mol}$, corresponding with the predicted mass of dimeric TxGH116-N (Figure S1C).

Confirmation of the anomeric configurations of the glucose product of TxGH116 and glucosyl azides produced in rescue of catalytic residue mutants: To check the anomeric configuration of glucose product, the enzyme $T x \mathrm{GH} 116 \Delta 1-18$ was exchanged with phosphate buffer in deuterium water $(\mathrm{pH} 6$, $10 \mathrm{mM}$ ) three times before running NMR experiments. For 4NPGlc hydrolysis experiment, $7.3 \mathrm{mM}$ 4NPGlc and $50 \mu \mathrm{M} T x \mathrm{GH} 116 \Delta 1-18$ were prepared in an NMR tube and the proton spectra collected before adding enzyme and after $10 \mathrm{~min}, 30 \mathrm{~min}$. and overnight reactions.

TxGH116 $\Delta 1-18$ wild type $(0.22 \mu \mathrm{M})$, D593A $(11 \mu \mathrm{M})$ and E441A $(44 \mu \mathrm{M})$ were incubated with $5 \mathrm{mM} 4 \mathrm{NPG}$ and $50 \mathrm{mM}$ azide in $50 \mathrm{mM}$ MES buffer $\mathrm{pH}$ 5.5. The reactions were incubated at $60{ }^{\circ} \mathrm{C}, 1 \mathrm{~h}$ for TxGH116 wild type and D593A, and $18 \mathrm{~h}$ for E441A. The reactions were terminated by 
boiling for $5 \mathrm{~min}$. Samples were centrifuged at 13,000 rpm for $10 \mathrm{~min}$ and then applied to silica gel thin layer chromatography (TLC) plates (Figure S5D). Plates were developed with chloroform$\mathrm{MeOH}-\mathrm{NH}_{4} \mathrm{OH}$ (7:2.8:0.2), and products detected using (a) UV light or (b) by exposure to $10 \%$ sulfuric acid in ethanol followed by charring.

For NMR analysis, $2 \mathrm{~mL}$ reactions were separated by silica gel TLC, as described above and the silica gel from the region of the product band was scraped off and eluted with $30 \%$ methanol, dried and redissolved in 100\% methanol and the supernatant dried for NMR. The purified glucosyl azides were dissolved in acetone-d6 and proton NMR spectra were performed on a $500 \mathrm{MHz} \mathrm{NMR}$ spectrometer (Bruker AVANCE III HD, Germany) with a CPP BBO 500 Cyroprobe. The ${ }^{1} \mathrm{H}$ NMR spectra were collected at a frequency of $500.366 \mathrm{MHz}$. The glucopyranosyl azide obtained from mutant D593A was confirmed as $\beta$-glucopyranosyl azide, its ${ }^{1} \mathrm{H}$ NMR were assigned as: $\delta 4.62(\mathrm{H} 1, \mathrm{~d}$, $\left.\mathrm{J}_{2,1}=8.6 \mathrm{~Hz}\right), \delta 3.93\left(\mathrm{H6}, \mathrm{dd}, \mathrm{J}_{5,6}=2.2 \mathrm{~Hz}, \mathrm{~J}_{6,6^{\prime}}=11.9 \mathrm{~Hz}\right), \delta 3.77\left(\mathrm{H6}^{\prime}, \mathrm{dd}, \mathrm{J}_{5,6^{\prime}}=5.2 \mathrm{~Hz}, \mathrm{~J}_{6,6^{\prime}}=11.9 \mathrm{~Hz}\right)$, $\delta$ 3.44-3.53 (H3, H4, H5, m), $\delta 3.28\left(\mathrm{H} 2, \mathrm{t}, \mathrm{J}_{1,2}=\mathrm{J}_{3,2}=8.7 \mathrm{~Hz}\right)$. The ${ }^{1} \mathrm{H}$ NMR spectrum matched the published for $\beta$-glucopyranosyl azide. ${ }^{10,11}$

The glucopyranosyl azide obtained from mutant E441A was confirmed as $\alpha$-glucopyranosyl azide, its ${ }^{1} \mathrm{H}$ NMR were assigned as: $\delta 5.48\left(\mathrm{H1}, \mathrm{d}, \mathrm{J}_{2,1}=3.3 \mathrm{~Hz}\right), \delta 3.87\left(\mathrm{H} 6, \mathrm{dd}, \mathrm{J}_{5,6}=2.6 \mathrm{~Hz}\right.$, $\left.\mathrm{J}_{6,6}=11.7 \mathrm{~Hz}\right), \delta 3.77\left(\mathrm{H}^{\prime}, \mathrm{dd}, \mathrm{J}_{5,6^{\prime}}=5.0 \mathrm{~Hz}, \mathrm{~J}_{6,6}=11.7 \mathrm{~Hz}\right), \delta 3.63-3.74(\mathrm{H} 3, \mathrm{H} 4, \mathrm{H} 5, \mathrm{~m}), \delta 3.44(\mathrm{H} 2$, $\left.\mathrm{t}, \mathrm{J}_{1,2}=\mathrm{J}_{3,2}=6.6 \mathrm{~Hz}\right)$. The ${ }^{1} \mathrm{H}$ NMR spectrum was similar to the reported for $\alpha$-glucopyranosyl azide. ${ }^{.2}$

Both $\alpha$ - and $\beta$-glucopyranosyl azides were injected into Bruker micrO-TOF-Q mass spectrometer (Q-TOF) to determine their mass spectra. The substrates dissolved in acetone-d6 (containing $0.1 \%$ formic acid) were injected directly to Electrospray ionization (ESI) source of QTOF mass spectrometer. The ESI source was performed at negative mode, the scan range of mass detector was $50-1500 \mathrm{~m} / \mathrm{z}$. The similar mass spectra were obtained for both azides. The $\mathrm{m} / \mathrm{z}$ of 204.066, 240.043 and 250.073 were assigned as $[\mathrm{M}-\mathrm{H}]^{-},[\mathrm{M}+\mathrm{Cl}]^{-}$and $\left[\mathrm{M}+\mathrm{HCO}_{2}\right]^{-}$, which was consisted with the reported data. ${ }^{10-12}$ 


\section{Supplementary Table}

Table S1 Oligonucleotide primers used for cloning and mutagenesis.

\begin{tabular}{|c|c|c|}
\hline \multicolumn{2}{|c|}{ Primer name } & Sequence \\
\hline \multicolumn{3}{|c|}{ Cloning primers } \\
\hline \multicolumn{2}{|c|}{ T7_long_Fwd } & TAATACGACTCACTATAGGGGAATTGTGAG \\
\hline \multicolumn{2}{|c|}{ TxGH116 No stop Rev } & CGCGCTCGAGCACTTCATTGTAGTTCACTTC \\
\hline \multicolumn{2}{|c|}{ Tx116_19_fwd } & CACCCCATGGCGCTGACGGGCTGTTCGGAAAAAATC \\
\hline \multicolumn{2}{|c|}{ Tx116_158_fwd } & CACCCCATGGCGAACAGTTGGTATACCTACACG \\
\hline \multicolumn{2}{|c|}{ Tx116_401_fwd } & CACCCCATGGCGGATTGGTATAAAACCGCGCTG \\
\hline \multicolumn{3}{|c|}{ Mutation primers } \\
\hline Mutation & Primer & Sequence \\
\hline \multirow[t]{2}{*}{$\mathrm{E} 441 \mathrm{~A}$} & Fwd & 5'-CCGGACCAGACCTACGCTACGTGGTCAATGAAA-3' \\
\hline & Rev & 5'-TTTCATTGACCACGTAGCGTAGGTCTGGTCCGG-3' \\
\hline \multirow[t]{2}{*}{ D593A } & Fwd & 5'-CATGTTCGGTCTGCTGGCATGCTTCGACTACAATT-3' \\
\hline & Rev & 5'-AATTGTAGTCGAAGCATGCCAGCAGACCGAACATG-3' \\
\hline \multirow[t]{2}{*}{ D508H } & Fwd & 5'-AGGGTATGATTCCGCATCATCTGGGCTCATCGTA-3' \\
\hline & Rev & 5'-TACGATGAGCCCAGATGATGCGGAATCATACCCT-3' \\
\hline \multirow[t]{2}{*}{ D508N } & Fwd & 5'-AGGGTATGATTCCGCATAATCTGGGCTCATCGTA-3' \\
\hline & Rev & 5'-TACGATGAGCCCAGATTATGCGGAATCATACCCT-3' \\
\hline \multirow[t]{2}{*}{ R544W } & Fwd & 5'-CGTGCTGCTGGTTTACTGGGACTATGTTCTGACCG-3' \\
\hline & Rev & 5'-CGGTCAGAACATAGTCCCAGTAAACCAGCAGCACG-3' \\
\hline \multirow[t]{2}{*}{$\mathrm{R} 786 \mathrm{H}$} & Fwd & '5'-GACGAAAGATGGCAATTATCACGCAAGTATGTATATGCGT-3' \\
\hline & Rev & 5'-ACGCATATACATACTTGCGTGATAATTGCCATCTTTCGTC-3' \\
\hline
\end{tabular}




\section{Supplementary Figures}

\section{Figure S1}
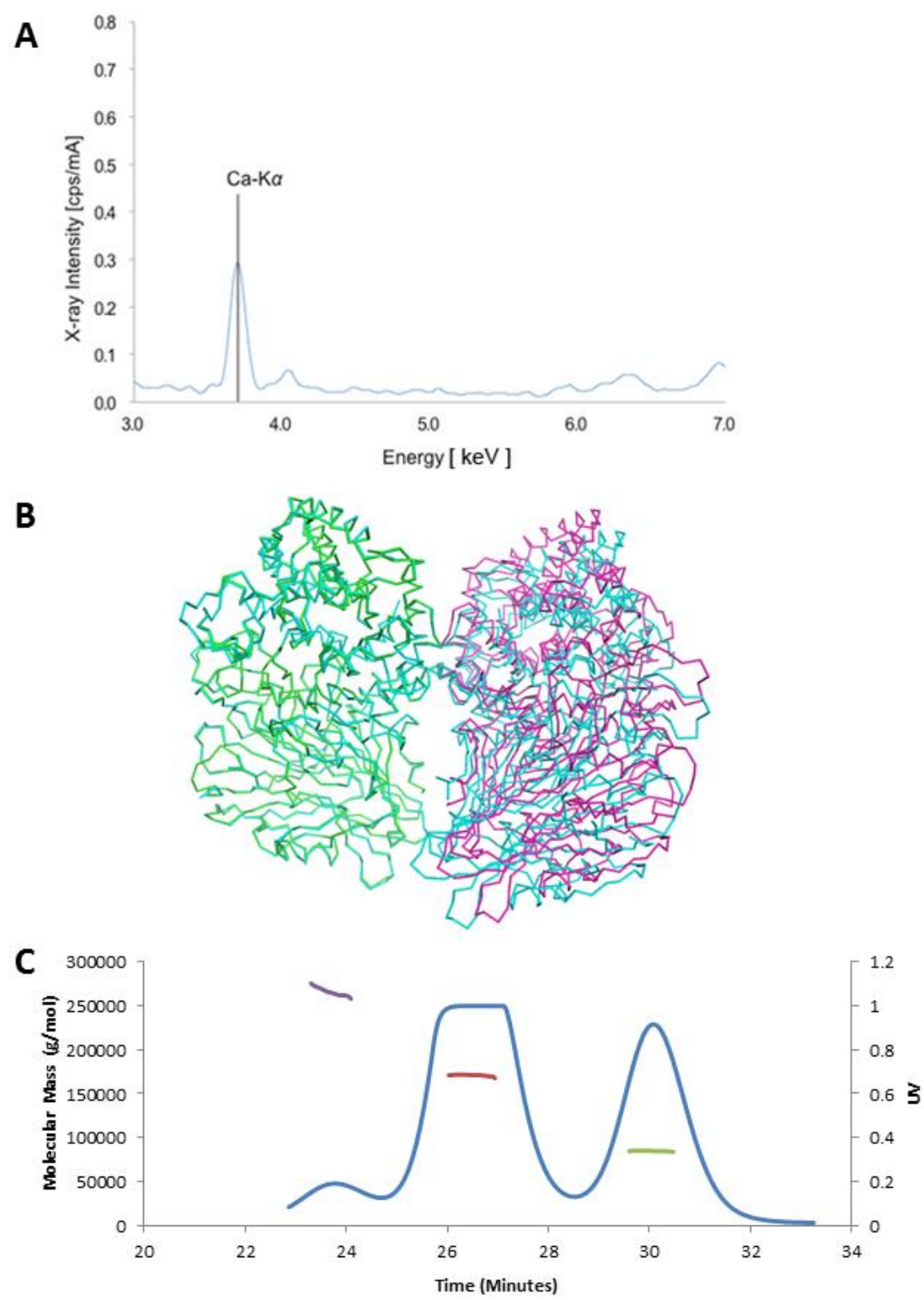

\section{Figure S1 Evidence for calcium binding and dimerization of TxGH116}

(A) Identification of calcium in $T x \mathrm{GH} 116$. To confirm the existence of calcium ions, purified Tx GH116 was analyzed by X-ray fluorescence. A dried sample was scanned using a Cartesian geometry energy dispersive X-ray fluorescence spectrometer, Rigaku NEX CG. A characteristic Ca$\mathrm{K} \alpha$ peak was detected showing the presence of $\mathrm{Ca}^{2+}$ ion in the sample. (B) Superposition of $T x \mathrm{GH} 116$ $P 2_{1} 2_{1} 2$ and $P 6_{1}$ structures showing the conserved interface between two symmetry mates in the $P 2_{1} 2{ }_{1} 2$ structure (green) and the A and B molecules of the asymmetric unit of the $P 6_{1}$ structure (cyan). The $P 6_{1}$ A molecule is nearly perfectly matched to the $P 2_{1} 2_{1} 2$ structure, to which it was superimposed, while the $\mathrm{B}$ molecule is only roughly aligned with the $P 2{ }_{1}{ }_{1} 2$ symmetry mate (violet), except at the dimer interface where it is well aligned. (C) Results from SEC-MALLS of TxGH116-N. There are three distinct peaks at $2.74 \times 10^{5} \mathrm{~g} / \mathrm{mol}, 1.66 \times 10^{5} \mathrm{~g} / \mathrm{mol}$ and $8.47 \times 10^{4} \mathrm{~g} / \mathrm{mol}$. $T x \mathrm{GH} 116-\mathrm{N}$ has a predicted mass of $9.27 \times 10^{4} \mathrm{~g} / \mathrm{mol}$. These data suggest that the dimer is the major form, although monomer and multimers exist. 
A
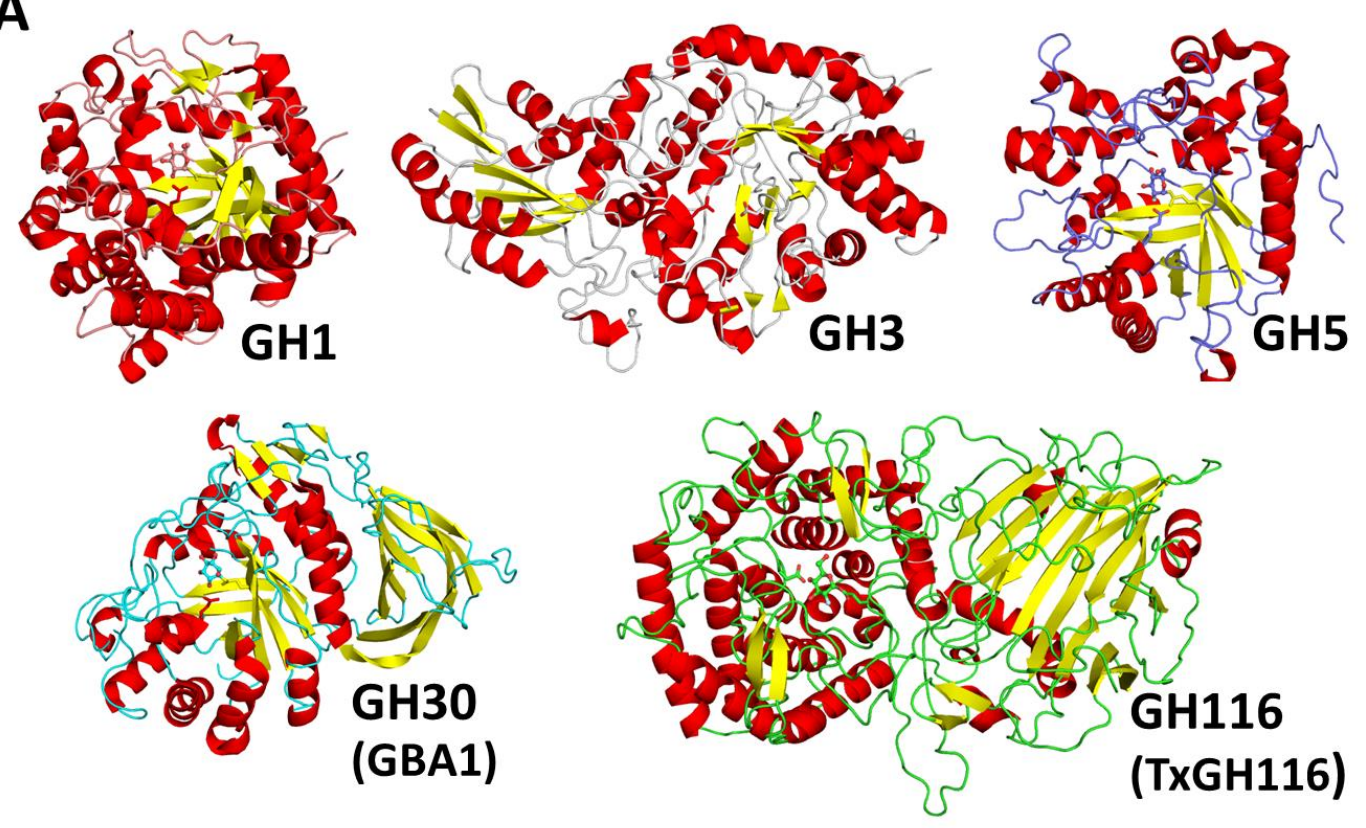

B
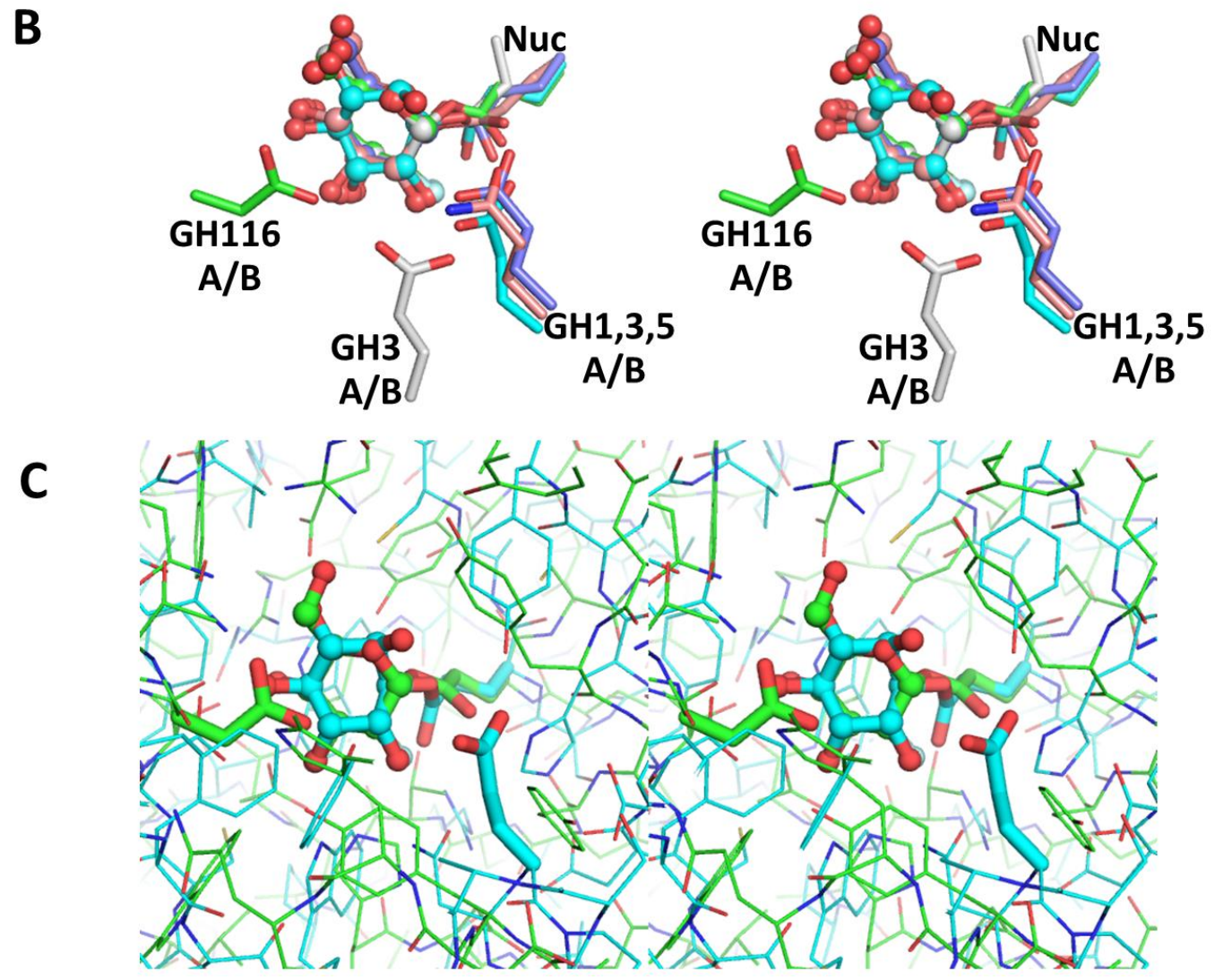

Figure S2 Uniqueness of $T x$ GH116 compared to other retaining $\beta$-glucosidases. (A) Comparison of the overall structure of $T x \mathrm{GH} 116$ to other retaining $\beta$-glucosidases. A GH2 structure is not shown, since no $\beta$-glucosidase structure from this family has been reported, but the catalytic domain structure of GH2 is similar to that in other GH Clan A families, including GH1, GH5 and GH30, based on GH2 $\beta$-galactosidase and $\beta$-mannosidase structures. (B) The stereo image of the superposition of the catalytic nucleophile (Nuc) and covalently linked sugar-like inhibitor show that the acid/base (A/B) of GH116 is in a completely different position in the active site compared to those in families GH1, 
GH3, GH5, and GH30. The superimposed structures in the stereo view include: TxGH116 2-deoxyfluoroglucosyl enzyme (green carbons) with the structures of human cytoplasmic $\beta$-glucosidase (GH1) E165Q mutant glucosyl-enzyme (pink, PDB code: 2Z0X), barley exoglucanase 1 (GH3) 2deoxy-2-fluoroglucosyl enzyme (grey, PDB code: 1IEW), Candida albicans exoglucanase (GH5) 2deoxy-2-fluoroglucosyl enzyme (dark blue, PDB code: 2PB1), and human GBA1 (GH30) covalently labeled with conduritol $\beta$-epoxide (cyan, PDB code: 1Y7V). (C) Stereo image of the active sites of Tx GH116 (green carbons) and human GBA1 (cyan, GH30, PDB code: 1Y7V) showing the difference in location of the catalytic acid/base and the absence of conserved sugar-binding residues. 

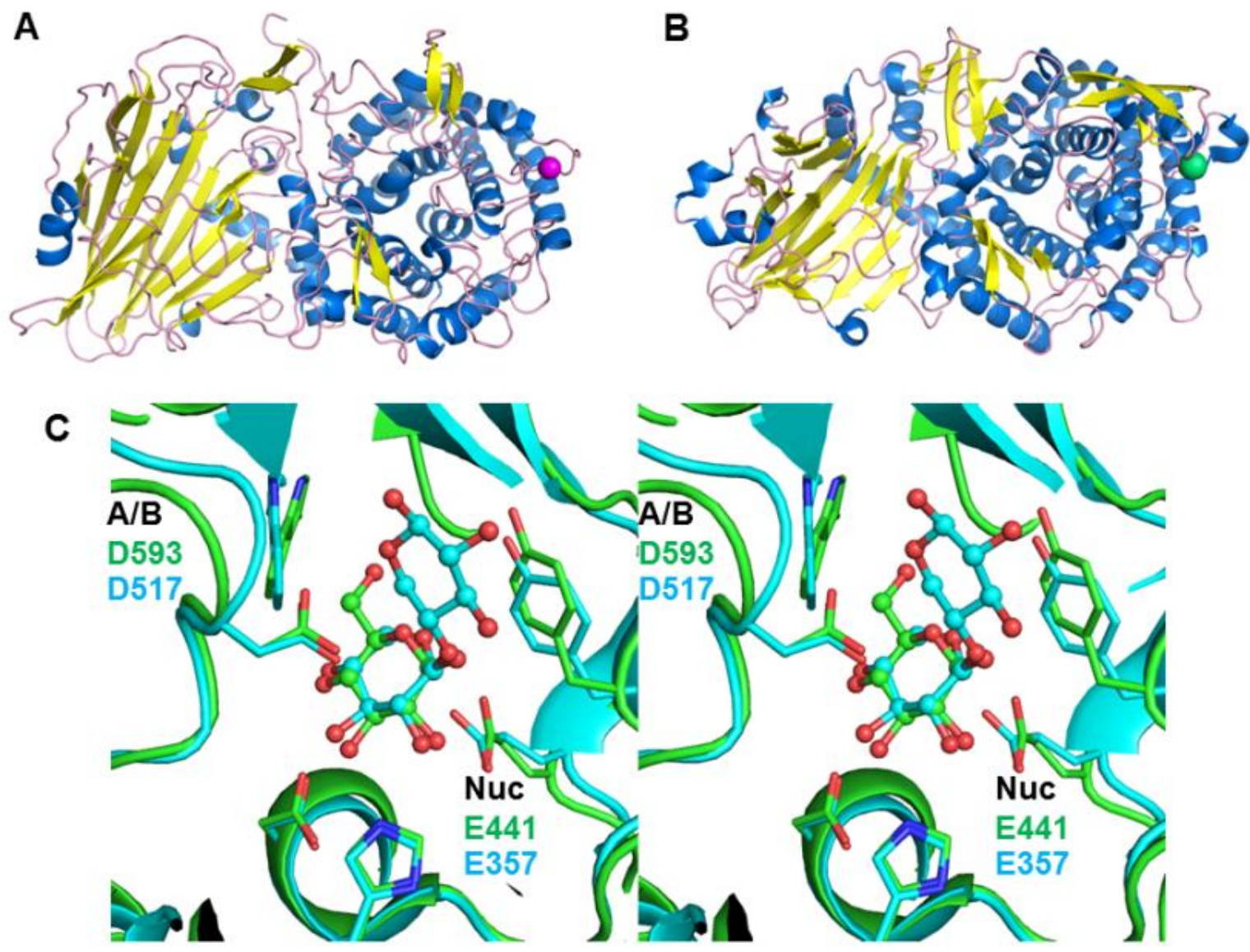

Figure S3. Comparison of the three-dimensional structures of TxGH116 $\beta$-glucosidase and the structurally related $\boldsymbol{G t G H 5 2} \beta$-xylosidase. $T x$ GH116 $\beta$-glucosidase (A) and GtGH52 $\beta$-xylosidase (B) exhibit similar overall folds. Both structures contain a metal binding site in nearly the same position, which was modeled as $\mathrm{Ca}^{2+}$ (purple ball) in $T x \mathrm{GH} 116$ and $\mathrm{Na}^{+}$(green ball) in GtGH52. ${ }^{3}$ The structures shown in (A) and (B) were superimposed in PyMol and the images rendered separately for clarity. Helices are in blue and $\beta$-strands in yellow. (C) Divergent stereo view of the active site superposition of the $T x \mathrm{GH} 116$ complex with Glc (green) with the GtGH52 complex with xylobiose (cyan). The catalytic acid/base (A/B) and nucleophile residues (Nuc) are labeled and other conserved active site residues simply shown. The structures were superimposed based on the catalytic residues and pyranose ring atoms in the glycone-binding site. 


\section{Figure S4}

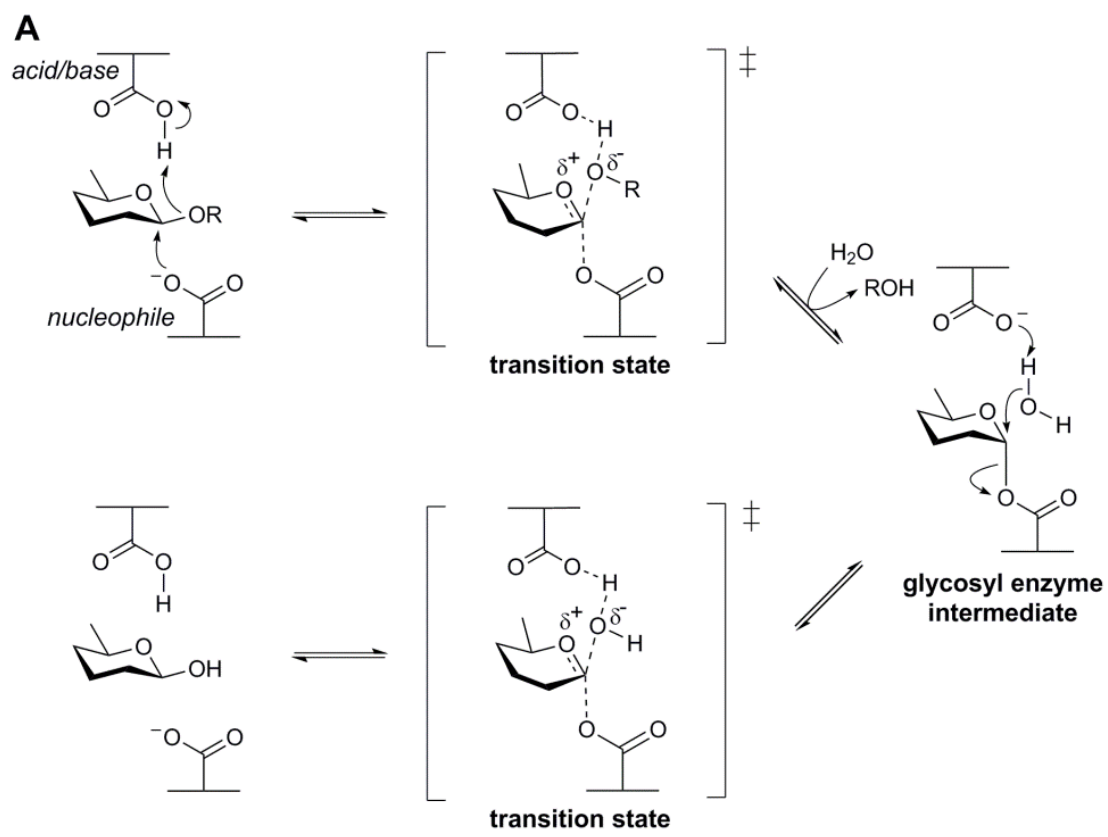

\section{B}

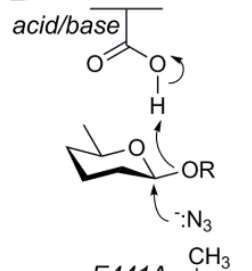

E441A $\mathrm{CH}_{3}$

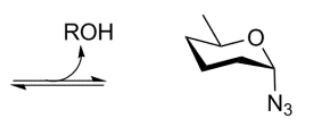

\section{C}

D593A $\mathrm{CH}_{3}$
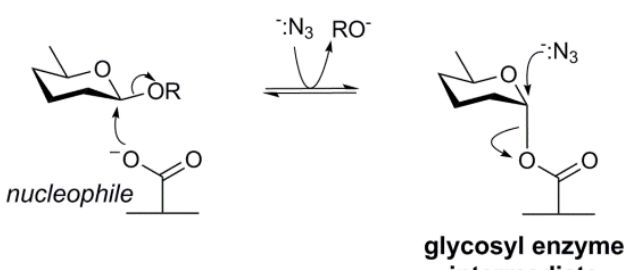

$\rightleftharpoons$ 的

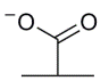

intermediate

Figure S4 Retaining mechanism of hydrolysis of family GH116 and chemical rescue of TxGH116 nucleophile and acid/base mutants. (A) The retaining mechanism follows two steps with oxocarbenium ion intermediates, glycosylation to form a covalent enzyme-sugar intermediate and deglycosylation to release the sugar from the enzyme. ${ }^{4}$ (B) Rescue of the catalytic nucleophile mutant (E441A) by the small nucleophile azide. (C) Rescue of the catalytic acid/base mutant by azide (or other small nucleophiles). The hydroxyl groups and hydrogens have been omitted from the sugar for clarity. 


\section{Figure S5}
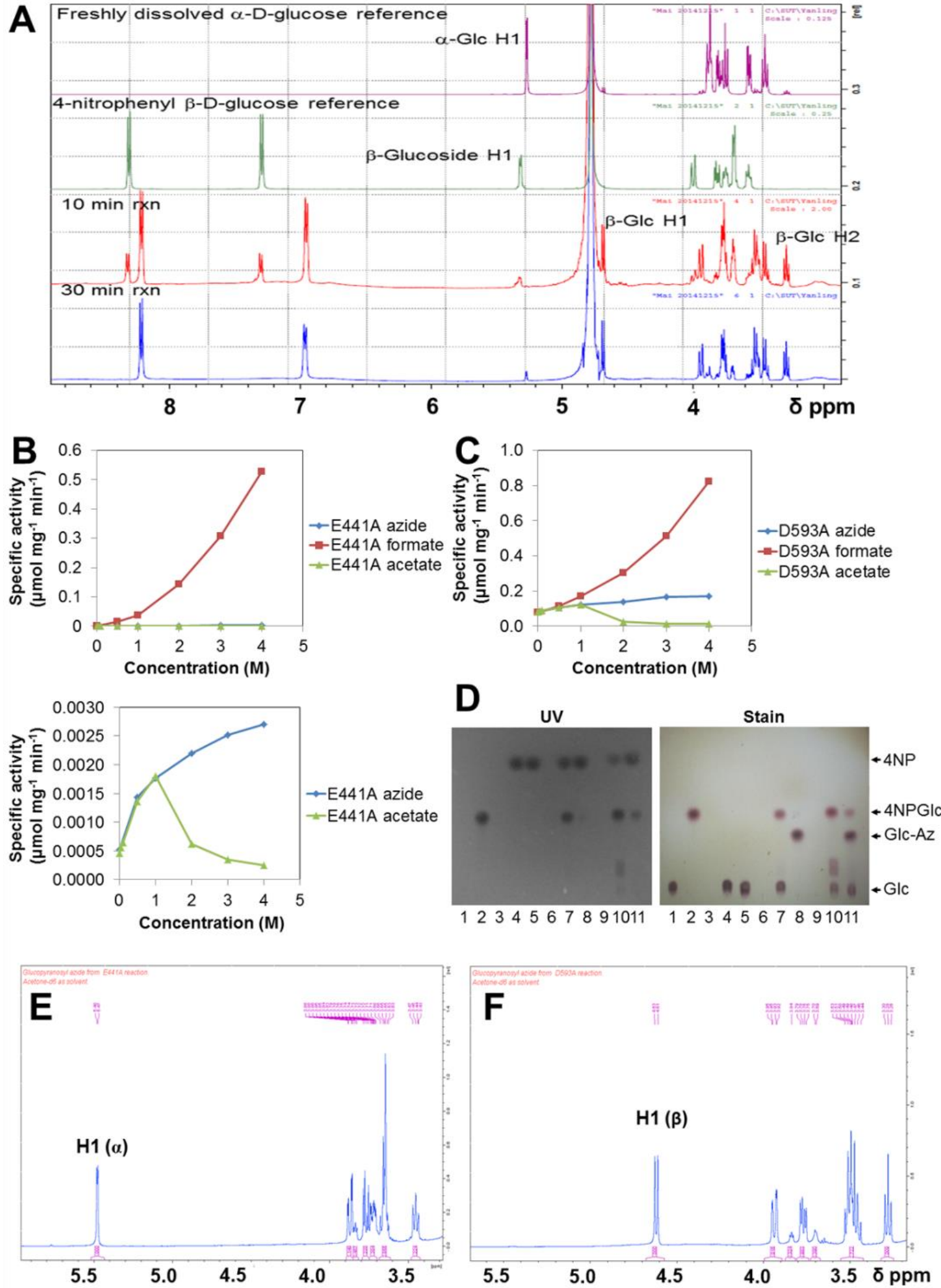

Figure S5: Evidence for $T x$ GH116 retaining mechanism and catalytic residues. (A) ${ }^{1} \mathrm{H}$ NMR spectra showing the $\beta$-anomeric form of glucose formed upon hydrolysis of 4NPGlc by TxGH116. (Top) Spectrum for $\alpha$-D-glucose, (second) spectrum for 4NPGlc, (third) spectrum 10 min after 
addition of enzyme, at which time a small amount of substrate remained and only $\beta$-D-glucose product could be detected, and (bottom) spectrum after $30 \mathrm{~min}$ of reaction, when all the substrate was consumed and a small amount of $\alpha$-D-glucose had formed by mutarotation, but the product was still $>90 \% \beta$-D-glucose. (B, C) Chemical Rescue of the activities of the TxGH116 mutant enzymes E441A (B) and D593A (C) by formate, acetate and azide. (D) Thin layer chromatographic analysis of the products of 4NPGlc reactions with azide catalyzed by $T x \mathrm{GH} 116$ wild type, D593A and E441A. Lane 1: standard glucose, lane 2: 4NPG/azide, lane 3: TxGH116/azide, lane 4: $T x \mathrm{GH} 116 / 4 \mathrm{NPG}$, lane 5: TxGH116/4NPG/azide, lane 6: D593A/azide, lane 7: D593A/4NPG, lane 8: D593A/4NPG/azide, lane 9: E441A/azide, lane 10: E441A/4NPG, and lane 11: E441A/4NPG/azide. (E) ${ }^{1} \mathrm{H}$ NMR spectrum of the glucosyl azide rescue product of $T x \mathrm{GH} 116 \mathrm{E} 441 \mathrm{~A}$ showing the $\alpha$-anomeric configuration. $(\mathbf{F}){ }^{1} \mathrm{H}$ NMR spectrum of the glucosyl azide rescue product of TxGH116 D593A showing the $\beta$-anomeric configuration. 


\section{Figure S6}

A

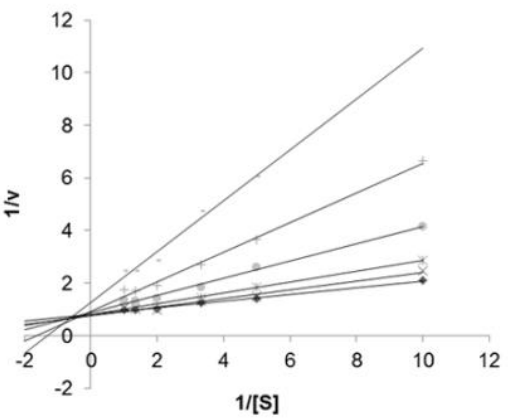

B

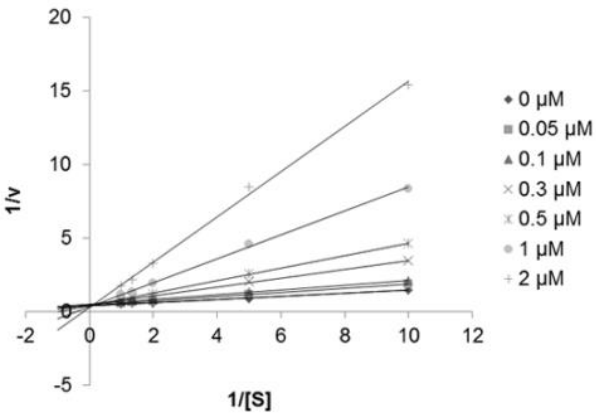

C

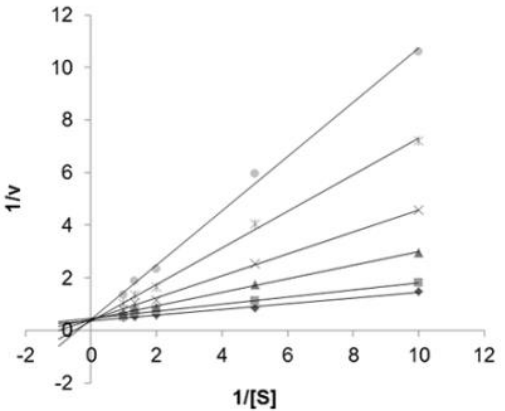

D

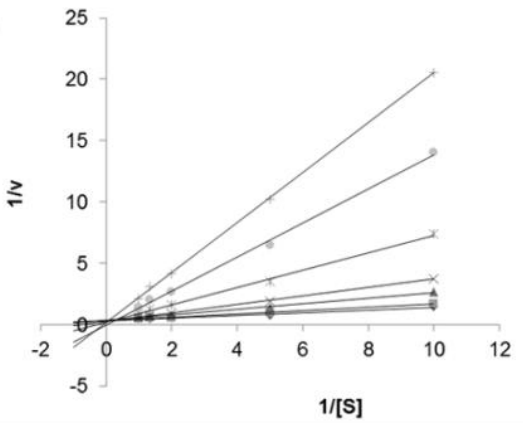

- $0 \mathrm{nM}$

$1 \mathrm{nM}$

$\times 2 \mathrm{nM}$

$10 \mathrm{nM}$

$10 \mathrm{nM}$
$20 \mathrm{nM}$
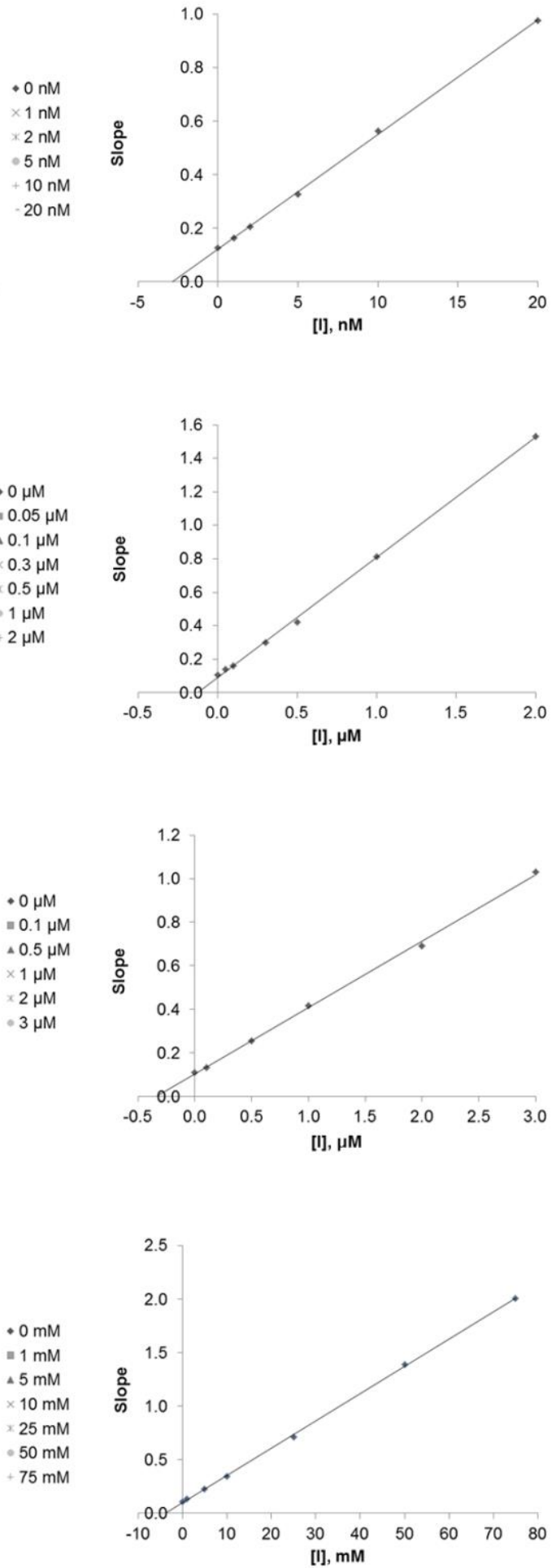

Figure S6 Inhibition of $\mathbf{T} x$ GH116. $T x \mathrm{GH} 116(4 \mathrm{nM})$ was pre-incubated with different concentrations of IFG (A), DNJ (B), GIM (C), and Glc (D) in $50 \mathrm{mM}$ sodium acetate, pH 5.5, at $37^{\circ} \mathrm{C}$ for $10 \mathrm{~min}$ and then assayed for release of 4NP from $0.1,0.2,0.5,0.75$, and $1 \mathrm{mM} 4 \mathrm{NPGlc}$ at $60^{\circ} \mathrm{C}$ for $10 \mathrm{~min}$. (Left) $1 / \mathrm{v}$ versus $1 /[\mathrm{S}]$ plot in the presence of different concentrations of an inhibitor. (Right) Replot of slope from reciprocal plot versus [I]. 


\section{Figure S7}

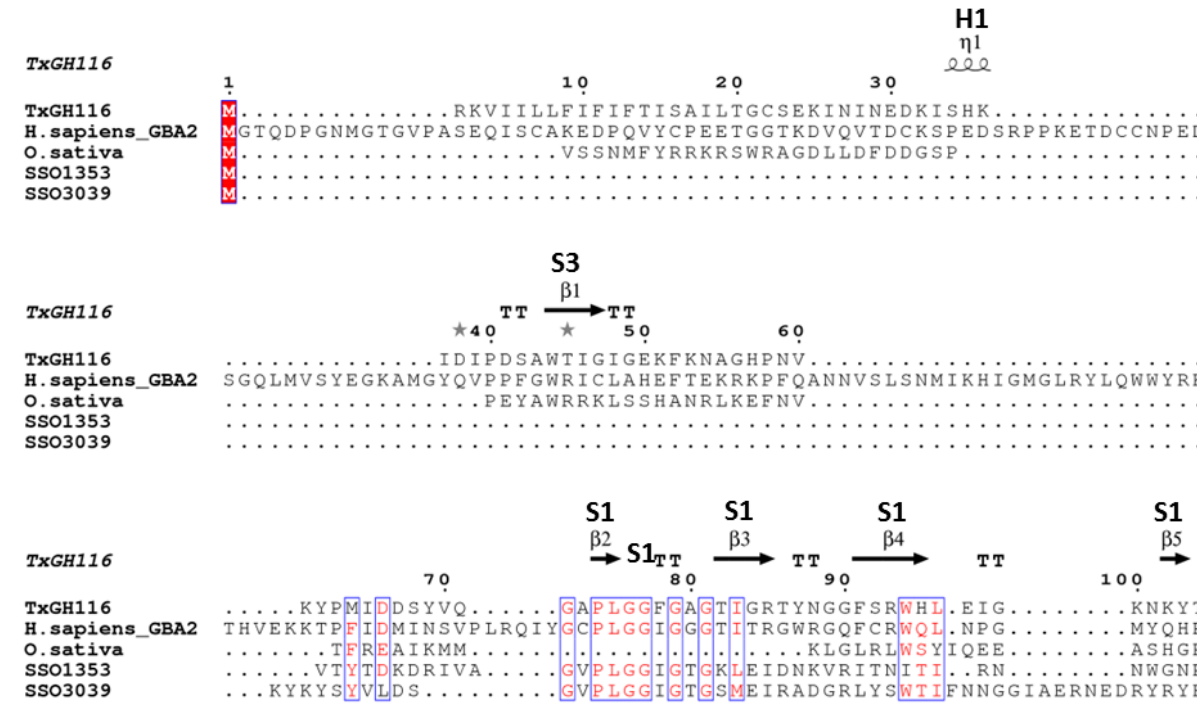

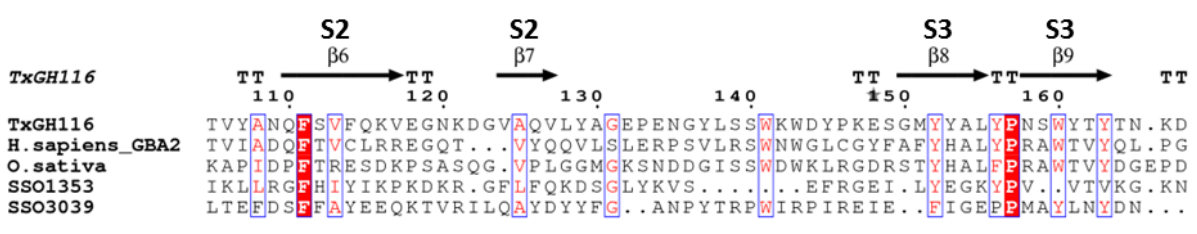
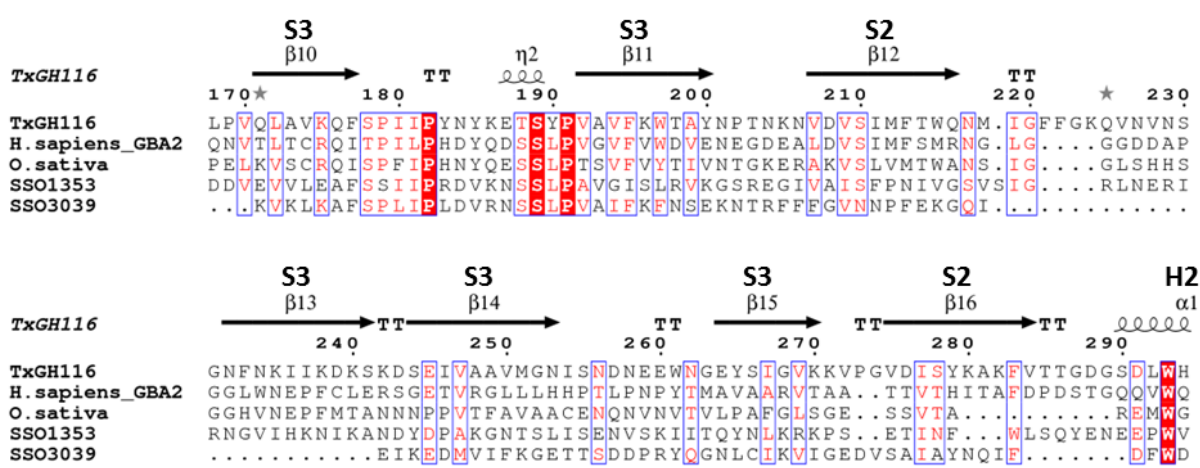

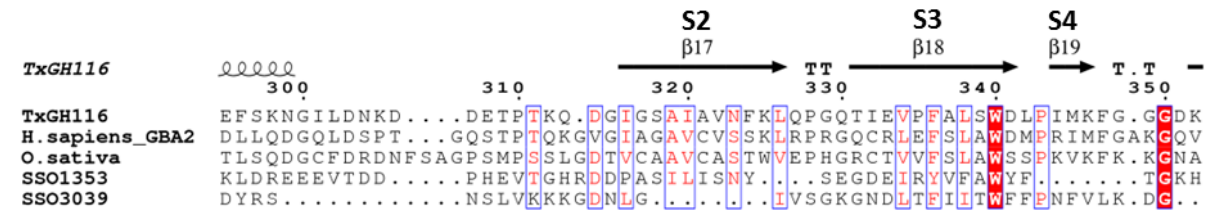

\begin{tabular}{|c|c|c|c|c|c|}
\hline & S4 & H3 & H4 & & H5 \\
\hline 6 & $\beta 2$ & $\begin{array}{l}\alpha 2 \\
\frac{12}{360}\end{array}$ & ${ }_{370}{ }_{\star}{ }_{380}^{\alpha 3}$ & $\mathrm{TT}_{400}$ & $\begin{array}{l}\alpha 4 \\
\text { peleleere } \\
\text { o }\end{array}$ \\
\hline $\begin{array}{l}\text { GH116 } \\
\text { sapiens_GBA2 } \\
\text { sativa } \\
01353 \\
03039\end{array}$ & $\begin{array}{l}\mathrm{Y}, 1 \\
Y Y \\
Y\end{array}$ & & 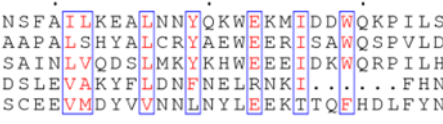 & $\begin{array}{l}\text { NKSKP } \\
\text { DRSLP } \\
\text { DERFP } \\
\text { IVNVK } \\
\text { AEGIE }\end{array}$ & 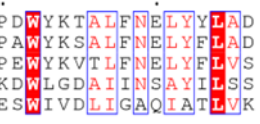 \\
\hline
\end{tabular}

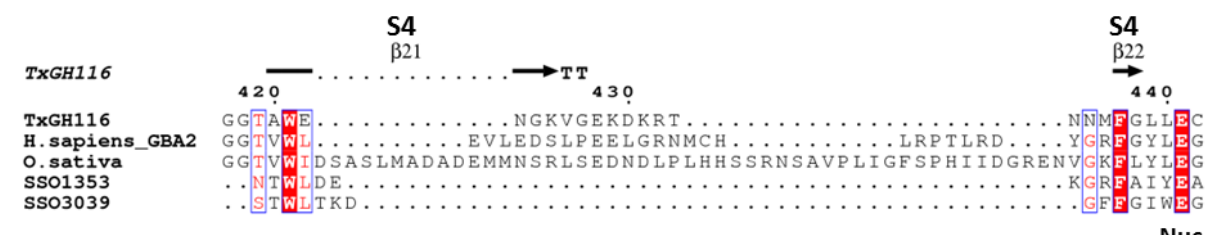


Figure S7 (continued)

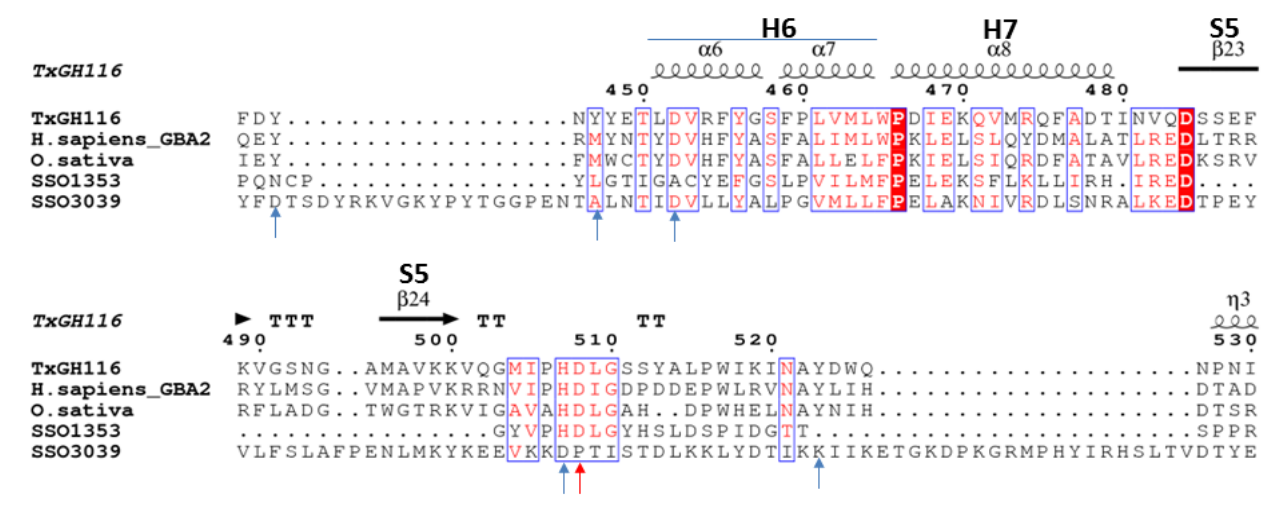

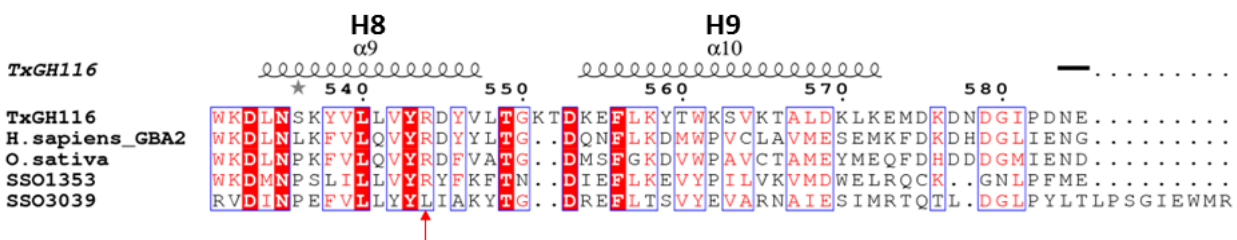

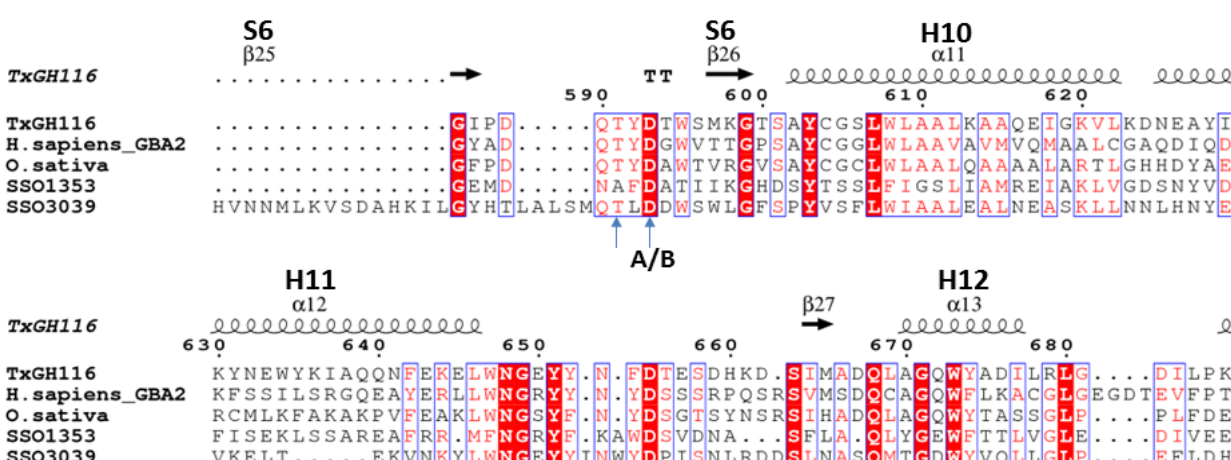

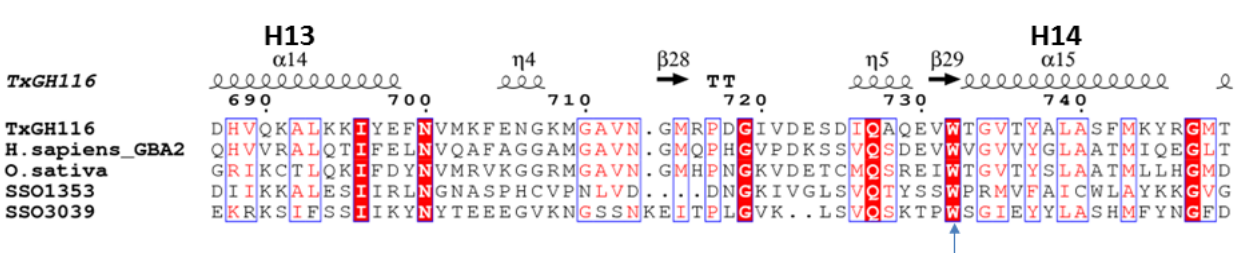

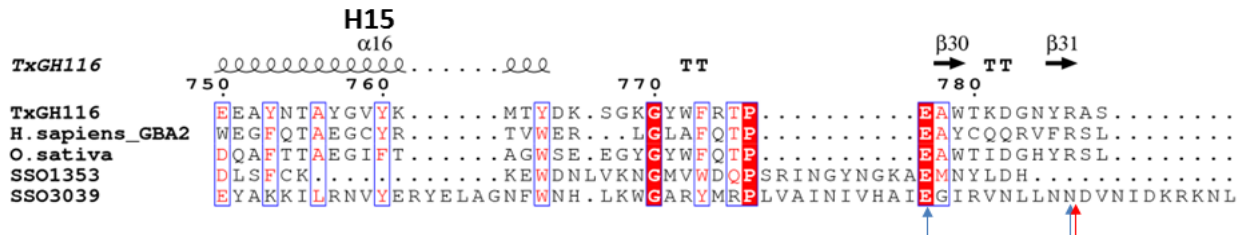

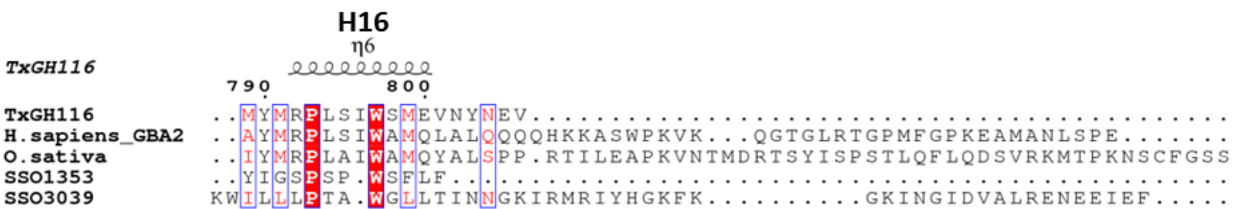

$\begin{array}{ll}\text { TxGH116 } & \\ & \\ \text { TxGH116 } & \ldots \ldots \\ \text { H.sapiens_GBA2 } & \therefore . . \\ \text { O.sativa } & \text { SSNCE } \\ \text { SSO1353 } & \ldots \ldots \ldots \\ \text { SSO3039 } & \ldots \ldots\end{array}$


Figure S7 Sequence alignment of TxGH116 with human GBA2, rice and archaeal GH116 glycosidase sequences. Active site residues are marked with grey arrows at the bottom of the alignment. Catalytic residues are marked with "Nuc" for nucleophile and "A/B" for acid/base. The residues mutated in missense mutations causing ARCA and HSP are marked with red arrows below the alignment. Other conserved residues are shown in black and grey depending on the degree of conservation. The alignment was produced with the MUSCLE algorithm within MEGA $6 .^{13,14}$ The secondary structure of $T x \mathrm{GH} 116$ is diagrammed above the alignment as interpreted by EsPriPT ${ }^{15}$ and the secondary structures identified in Figure 1 are indicated above these designations ( $\mathrm{H}$ for helix and $\mathrm{S}$ for $\beta$-sheet, for which multiple strands are marked for each). Small $\beta$-sheets with no strands more than 2 residues were ignored in our designations. The sequences include those of TxGH116 (NCBI Accession: AEF18218.1), human (Homo sapiens) GBA2 (NCBI: NP 065995.1), rice (Oryza sativa) expressed GH116 protein (NCBI: EEC81952.1), Sulfolobus solfataricus SSO3039 $\beta-N$ acetylglucosaminidase (NCBI: AAK43141.1) and $S$. solfataricus SSO1353 $\beta$-xylosidase/ $\beta$ glucosidase (NCBI: AAK41589.1). The alignment of SSO3039 was manually modified to match the nucleophile assignment of ${ }^{16}$ and improve its match to the other sequences. 


\section{Figure S8}
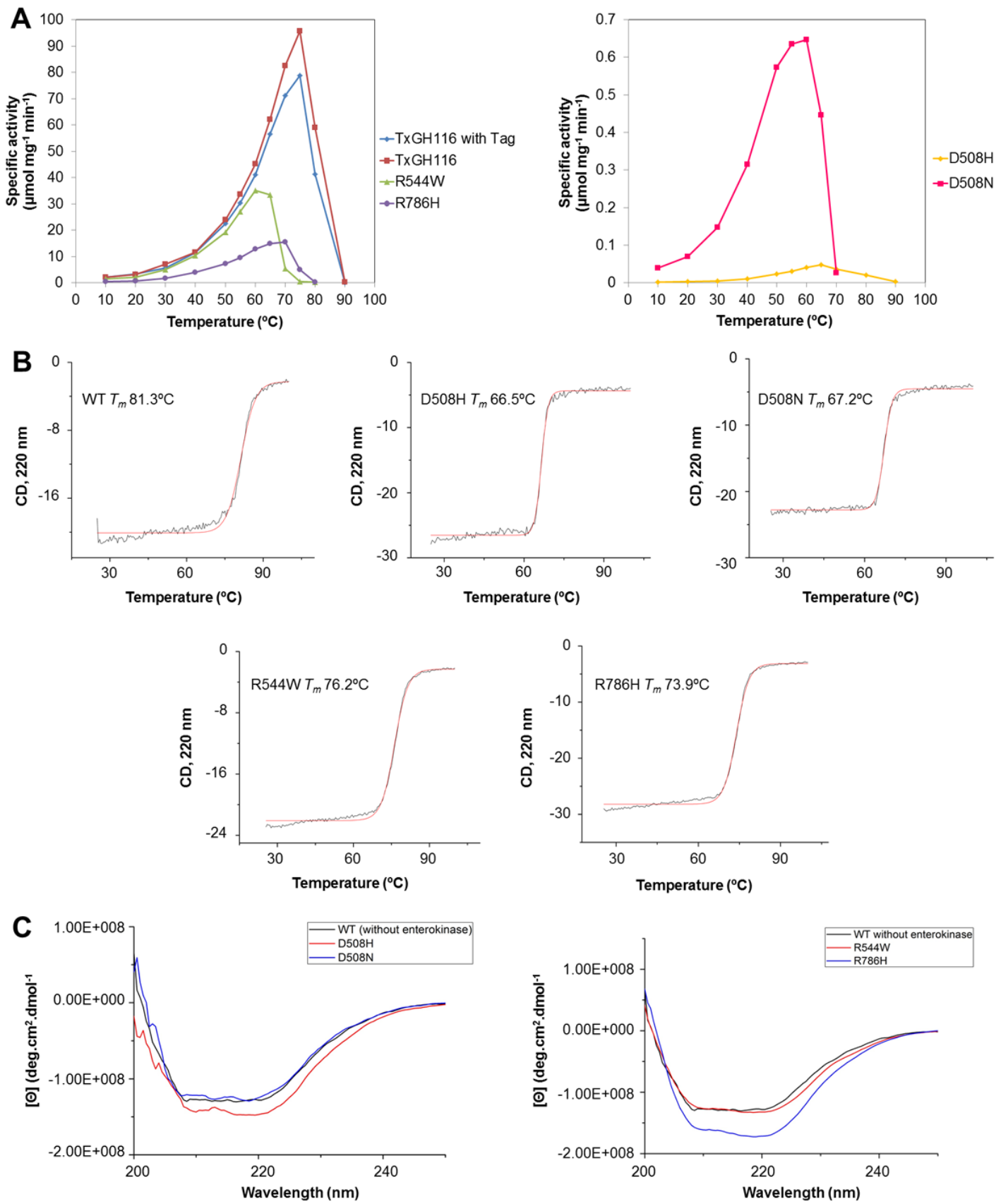

Figure S8 Temperature effects on TxGH116 wild type and mutants. (A) Temperature optima of $T x \mathrm{GH} 116$ wild type and mutant enzymes. (B) Melting curves for wild type TxGH116 and human-like mutants for full-length (undigested) proteins monitored by circular dichroism at $220 \mathrm{~nm}$. (C) All mutant proteins showed similar circular dichroism spectra to the wild type, suggesting minimal disruption of the structure at $20{ }^{\circ} \mathrm{C}$. Circular dichroism spectra of wild type (WT, TxGH116 $\Delta 1-18$ ) and its D508H and D508N mutant proteins (left) and wild type with R544W and R786H mutants (right). The CD spectra and melting curves were determined for enzymes without removal of the Nterminal hexa-histidine and S-tags, since the D508H and D508N mutants were not stable after enterokinase treatment. 


\section{SI References}

[1] Sansenya, S., Mutoh, R., Charoenwattanasatien, R., Kurisu, G., and Ketudat Cairns, J. R. (2015) Expression and crystallization of a bacterial glycoside hydrolase family $116 \beta$-glucosidase from Thermoanaerobacterium xylanolyticum, Acta Crystallogr F Struct Biol Commun 71, 4144.

[2] Emanuelsson, O., Brunak, S., von Heijne, G., and Nielsen, H. (2007) Locating proteins in the cell using TargetP, SignalP and related tools, Nat Protocols2, 953-971.

[3] Espina, G., Eley, K., Pompidor, G., Schneider, T. R., Crennell, S. J., and Danson, M. J. (2014) A novel $\beta$-xylosidase structure from Geobacillus thermoglucosidasius: the first crystal structure of a glycoside hydrolase family GH52 enzyme reveals unpredicted similarity to other glycoside hydrolase folds, Acta Crystallogr D Biol Crystallogr 70, 1366-1374.

[4] Ly, H. D., and Withers, S. G. (1999) Mutagenesis of glycosidases, Annu Rev Biochem 68, 487522.

[5] Tankrathok, A., Iglesias-Fernández, J., Williams, R. J., Pengthaisong, S., Baiya, S., Hakki, Z., Robinson, R. C., Hrmova, M., Rovira, C., Williams, S. J., and Ketudat Cairns, J. R. (2015) A single glycosidase harnesses different pyranoside ring transition state conformations for hydrolysis of mannosides and glucosides, ACS Catal. 5, 1041-1051.

[6] Davies, G. J., Dauter, M., Brzozowski, A. M., Bjornvad, M. E., Andersen, K. V., and Schulein, M. (1998) Structure of the Bacillus agaradherans family 5 endoglucanase at $1.6 \AA$ and its cellobiose complex at 2.0 Å resolution, Biochemistry 37, 1926-1932.

[7] Davies, G. J., Ducros, V. M., Varrot, A., and Zechel, D. L. (2003) Mapping the conformational itinerary of $\beta$-glycosidases by X-ray crystallography, Biochem Soc Trans 31, 523-527.

[8] Davies, G. J., Planas, A., and Rovira, C. (2012) Conformational analyses of the reaction coordinate of glycosidases, Acc Chem Res 45, 308-316.

[9] Speciale, G., Thompson, A. J., Davies, G. J., and Williams, S. J. (2014) Dissecting conformational contributions to glycosidase catalysis and inhibition, Curr Opin Struct Biol 28c, 1-13.

[10] Wang, Q., Trimbur, D., Graham, R., Warren, R. A., and Withers, S. G. (1995) Identification of the acid/base catalyst in Agrobacterium faecalis $\beta$-glucosidase by kinetic analysis of mutants, Biochemistry 34, 14554-14562.

[11] Hua, Y., Sansenya, S., Saetang, C., Wakuta, S., and Cairns, J. R. K. (2013) Enzymatic and structural characterization of hydrolysis of gibberellin A4 glucosyl ester by a rice $\beta$-Dglucosidase, Arch Biochem Biophys 537, 39-48.

[12] Wang, Q., Graham, R. W., Trimbur, D., Warren, R. A. J., and Withers, S. G. (1994) Changing enzymic reaction mechanisms by mutagenesis: conversion of a retaining glucosidase to an inverting enzyme, J Am Chem Soc 116, 11594-11595. 
[13] Edgar, R. C. (2004) MUSCLE: multiple sequence alignment with high accuracy and high throughput, Nucleic Acids Res 32, 1792-1797.

[14] Tamura, K., Stecher, G., Peterson, D., Filipski, A., and Kumar, S. (2013) MEGA6: Molecular Evolutionary Genetics Analysis version 6.0, Mol Biol Evol 30, 2725-2729.

[15] Gouet, P., Courcelle, E., Stuart, D. I., and Metoz, F. (1999) ESPript: analysis of multiple sequence alignments in PostScript, Bioinformatics 15, 305-308.

[16] Ferrara, M. C., Cobucci-Ponzano, B., Carpentieri, A., Henrissat, B., Rossi, M., Amoresano, A., and Moracci, M. (2014) The identification and molecular characterization of the first archaeal bifunctional exo- $\beta$-glucosidase/ $\mathrm{N}$-acetyl- $\beta$-glucosaminidase demonstrate that family GH116 is made of three functionally distinct subfamilies, Biochim Biophys Acta 1840, 367-377. 